\title{
A educação superior brasileira: dilemas, desafios e comparações com os países da OCDE e do BRICS*
}

\author{
NELSON CARDOSO AMARAL \\ Universidade Federal de Goiás, Goiânia, GO, Brasil
}

\section{RESUMO}

O estudo apresenta uma análise de um conjunto de dilemas e de desafios da educação superior brasileira relacionados às seguintes temáticas: privatização; taxas líquidas e brutas de escolarização; limites socioeconômicos à expansão tanto pública quanto privada; relação candidato/vaga; vagas não preenchidas; financiamento no contexto do novo Plano Nacional de Educação (PNE) e comparações com diversos países-membros da Organização para a Cooperação e Desenvolvimento Econômico (OCDE) e do BRICS (Brasil, Rússia, Índia, China e África do Sul). Os resultados das análises mostram que, em geral, são grandes os desafios do Brasil quando comparados seus indicadores com os países da OCDE. Pode-se concluir que só será possível atingir os parâmetros da OCDE quando ocorrerem, simultaneamente, três efeitos: estabilidade da população com a diminuição de crianças e jovens em idade educacional; crescimento do país e de seu produto interno bruto (PIB) no contexto do capitalismo mundial; e diminuição das desigualdades sociais existentes.

\section{PALAVRAS-CHAVE}

educação superior; indicadores; percentual do PIB; orçamento.

* Estudo apresentado na 36a Reunião Anual da Associação Nacional de Pós-Graduação e Pesquisa em Educação (ANPEd), na seção conjunta de Grupos de Trabalho (GT05, GT09 e GT11), realizada em Goiânia no ano de 2013. 


\title{
HIGHER EDUCATION IN BRAZIL: DILEMMAS, CHALLENGES AND COMPARISON WITH OECD AND BRICS COUNTRIES
}

\begin{abstract}
This study presents an analysis of a set of dilemmas and challenges for higher education in Brazil related to the following topics: privatization; net and gross schooling rates; socioeconomic limits to both public and private growth; applicants/vacancy relation; unfulfilled vacancies; financial support within the context of the new Plano Nacional de Educação (PNE); and comparisons amongst different Organization for Economic Co-operation and Development (OECD) and BRICS countries (Brazil, Russian, Indian, China and South Africa). The results analysis reveals that, in general terms, Brazil faces big challenges when compared to OECD countries. We can conclude that it will be possible to achieve OECD parameters when three effects occur simultaneously: stability of child and young population at school age; growth of the country and of the gross domestic product (GDP) within the context of world capitalism; and the decrease of social inequalities.
\end{abstract}

KEYWORDS

higher education; indexes; GDP percentage; budget.

\section{LA EDUCACIÓN SUPERIOR BRASILEÑA: DILEMAS, RETOS Y COMPARACIONES CON LOS PAÍSES DE OCDE Y BRICS}

\section{RESUMEN}

El estudio presenta un análisis de un conjunto de dilemas y retos de la educación superior brasileña relacionados a las siguientes temáticas: privatización; tasas netas y brutas de escolarización; límites socioeconómicos a la expansión tanto pública como privada; relación candidatos/plazas; plazas no completadas; financiación en el contexto del nuevo Plano Nacional de Educação (PNE) y comparaciones con varios países miembros de la Organização para la Cooperación y Desarrollo Económicos (OCDE) y de los BRICS (Brasil, Rusia, India, China y Sudáfrica). Los resultados de los análisis muestran que, por lo general, son grandes los retos de Brasil cuando se comparan sus indicadores con los de países de la OCDE. Se puede concluir que sólo será posible alcanzar los parámetros de la OCDE cuando se den, simultáneamente, tres efectos: estabilidad de la población por la disminución de niños y jóvenes en edad escolar; crecimiento del país y de su producto interno bruto (PIB) en el contexto del capitalismo mundial; y disminución de las desigualdades sociales existentes.

PALABRAS CLAVE

educación superior; indicadores; porcentual del PIB; presupuesto. 


\section{INTRODUÇÃO}

A educação superior foi implantada de forma definitiva no Brasil a partir de 1920, quando da instalação da Universidade do Rio de Janeiro, que foi transformada na Universidade do Brasil em 1937 (Fávero, 2000, p. 12). Até 1964, início da ditadura militar, a educação superior brasileira contava com um pequeno número de matrículas, apenas 142.386 (Barros, 2007,p. 13), para um contingente de 7.142.443 jovens com idade entre 15 e 19 anos, de 6.160 .742 jovens com idade entre 20 e 24 anos e de 5.208 .742 com idade entre 25 e 29 anos, considerando dados do censo de 1960 - não existem dados disponíveis para o ano de 1964 (Brasil, s.d.).

Se considerarmos que a metade dos jovens com idade de 15 a 19 anos possui idade entre 18 e 19 anos, teríamos em 1960 um total de 9.731 .964 jovens com idade entre 18 e 24 anos, período adequado para que as pessoas frequentem um curso de graduação. Considerando que existiam 142.386 estudantes matriculados, para um contingente de 9.783 .964 jovens com idade entre 18 e 24 anos, concluímos que o Brasil possuía no início dos anos 1960 uma baixíssima taxa bruta na educação superior, em torno de $1,5 \%$.

Foi, portanto, somente a partir de 1964 que foram promovidas ações que expandissem a educação superior, chegando em 2013 com instituições de educação superior (IES) instaladas em todos os estados da federação e com uma taxa bruta de 28,2\%, considerando-se as informações do Censo da Educação Superior de 2011. Pode-se afirmar que essa taxa ainda é pequena, e o projeto de lei n. 8.035/2010, que apresenta a proposta de um novo Plano de Educação Nacional (PNE), tem como meta atingir $50 \%$ de taxa bruta, no final da década de sua validade - contada a partir do ano de aprovação do projeto de lei.

No percurso de tempo, de 1964 a 2011, em que a educação superior brasileira passou de 142.386 estudantes matriculados para 6.739.689, e a taxa bruta, de 1,5\% para 28,2\%, acumularam-se dilemas e desafios que se apresentam aos dirigentes institucionais, governantes - poderes Executivo e Legislativo - e à sociedade.

A literatura acadêmica que discute a educação superior brasileira destaca problemas que significam verdadeiros desafios a serem enfrentados: a grande privatização das matrículas; as baixas taxas líquida e bruta; o pequeno percentual de jovens que frequentam IES que desenvolvem ensino, pesquisa e extensão; o elevado quantitativo de professores contratados em tempo parcial; o baixo número de professores contratados com o título de doutor; a elevação dos recursos públicos que se dirigem às IES privadas; a baixa relação aluno/professor; a grande evasão dos estudantes, principalmente os de licenciatura; a implantação de um processo de avaliação que privilegia um exame de larga escala em detrimento de processos avaliativos mais amplos e abrangentes; a mercantilização da educação superior; a inadimplência dos estudantes das IES privadas; o elevado custo das universidades de pesquisa; a isonomia salarial e a carreira única nas IES federais; o corporativismo existente no interior das IES; a pressão exercida pela mundialização do capital com a intenção de padronizar a constituição e a atuação das IES; a necessidade de internacionalizar as atividades das instituições, a grande assimetria existente entre e nas regiões brasileiras etc. 
Em meio a tantos problemas que explicitam diversos dilemas e desafios tão diferenciados, analisaremos neste estudo as seguintes vertentes:

a) o tamanho da educação superior brasileira e seu financiamento;

b) a privatização;

c) as taxas líquidas e brutas de escolarização;

d) o limite à expansão pública e privada;

e) a relação candidato/vagas oferecidas;

f) as vagas não preenchidas;

g) o financiamento das IES no contexto de um novo PNE;

h) o valor aplicado em educação superior por pessoa em idade educacional, comparando com diversos países.

Neste estudo, sempre que possível, analisaremos indicadores associados à educação superior no Brasil e teceremos comparações com os países que compõem a Organização para a Cooperação e Desenvolvimento Econômico (OCDE) e com os países que fazem parte do BRICS (Brasil, Rússia, Índia, China e África do Sul). Os países da OCDE são aqueles mais ricos do mundo e possuem uma renda per capita média de US\$/PPP ${ }^{1} 34.062,00$, e os países que compõem o BRICS, com renda per capita média de US\$/PPP 10.280,00, que cada vez mais se fazem presentes no cenário internacional.

Entre os países que compõem a OCDE examinaremos, em separado, os indicadores do Chile, da Hungria, do México e da Turquia, pois, apesar de fazerem parte da OCDE, possuem rendas per capita mais próximas às dos BRICS (EUA, 2010). Denominaremos o conjunto de países-membros da OCDE, retirando-se esses quatro países, de "bloco" OCDE.

Ao examinarmos diversos indicadores relativos à educação superior, poderemos perceber as diferenças existentes entre o Brasil e os outros países que compõem o BRICS e aqueles do "bloco" OCDE, que já possuem uma situação cristalizada no contexto da constituição mundial em uma sociedade estruturada no modo capitalista de produção (Harvey, 2000, p. 131).

Iremos, em primeiro lugar, analisar o tamanho do desafio educacional brasileiro, considerando o quantitativo da população a ser educada para, em seguida, analisar as seguintes temáticas relativas à educação superior: a privatização e as taxas líquida e bruta; o limite socioeconômico para a expansão da educação superior brasileira em que se discute sobre as vagas não preenchidas e a relação candidatos/ vagas; o financiamento da educação superior no novo PNE; e, nas considerações finais, comparar os recursos públicos aplicados em educação superior no Brasil e outros países, além de projetar, até 2050, como seria o financiamento da educação superior se o país aplicasse $10 \%$ do produto interno bruto (PIB) em educação, em todos os níveis, etapas e modalidades.

1 Os valores US\$/PPP são aqueles valores em dólares que sofreram correções para obter a paridade do poder de compra (Purchasing Power Parity - PPP). 


\section{O TAMANHO DO DESAFIO EDUCACIONAL BRASILEIRO}

Podemos examinar o tamanho dos desafios educacionais de um país considerando os percentuais do PIB que são aplicados em educação e calculando o valor aplicado por pessoa em idade educacional. $\mathrm{O}$ quantitativo de pessoas em idade educacional é obtido adicionando-se aqueles em idade de creche e pré-escola, idade de 0 a 5 anos, em idade de ensino fundamental, 6 a 14 anos, em idade de ensino médio, 15 a 17 anos, e em idade de educação superior, 18 a 24 anos.

O Quadro 1 mostra o valor aplicado por pessoa em idade educacional e o fator multiplicativo para atingir-se o valor dos países do "bloco" OCDE. Pode-se considerar que, quanto maior o fator multiplicativo, maiores serão os desafios educacionais para aquele país.

Quadro 1 - Valor aplicado por pessoa em idade educacional e fator multiplicativo para atingir o valor da OCDE

\begin{tabular}{|l|c|c|c|c|c|c|}
\hline \multicolumn{1}{|c|}{ País } & $\begin{array}{c}\text { PIB } \\
\text { (US\$/PPP } \\
\text { em bilhões) } \\
2011\end{array}$ & $\begin{array}{c}\text { PIB aplicado } \\
\text { em } \\
\text { educação } \\
\text { (\%) }\end{array}$ & $\begin{array}{c}\text { População } \\
\text { em idade } \\
\text { educacional }\end{array}$ & $\begin{array}{c}\text { Valor } \\
\text { aplicado em } \\
\text { educação em } \\
\text { bilhões } \\
\text { (US\$/PPP) }\end{array}$ & $\begin{array}{c}\text { Valor aplicado } \\
\text { por pessoa } \\
\text { em idade } \\
\text { educacional } \\
\text { (US\$/PPP) }\end{array}$ & $\begin{array}{c}\text { Fator de } \\
\text { multiplicação } \\
\text { para atingir } \\
\text { 0 valor da } \\
\text { OCDE }\end{array}$ \\
\hline Brasil & 2.024 & 4,0 & 84.400 .000 & 81,09 & 959,00 & 8,3 \\
\hline $\begin{array}{l}\text { "Bloco" } \\
\text { OCDE }\end{array}$ & 39.675 & 5,17 & 257.833 .181 & $2.050,03$ & $7.950,98$ & 1,0 \\
\hline Rússia & 2.380 & 3,9 & 35.043 .319 & 92,82 & $2.648,72$ & 3,0 \\
\hline Índia & 4.463 & 3,1 & 557.261 .930 & 138,353 & 248,27 & 32,0 \\
\hline China & 11.290 & 3,3 & 415.339 .912 & 372,57 & 897,02 & 8,9 \\
\hline $\begin{array}{l}\text { África } \\
\text { do Sul }\end{array}$ & 555 & 5,4 & 20.105 .821 & 29,97 & $1.490,61$ & 5,3 \\
\hline Chile & 281 & 4,0 & 5.380 .607 & 11,24 & $2.088,98$ & 3,8 \\
\hline Hungria & 195 & 5,2 & 2.661 .708 & 10,16 & $3.815,44$ & 2,1 \\
\hline México & 1.657 & 4,8 & 41.354 .774 & 79,54 & $1.923,26$ & 4,1 \\
\hline Turquia & 1.026 & 2,9 & 24.266 .277 & 29,75 & $1.226,15$ & 6,5 \\
\hline
\end{tabular}

Fonte: Organização das Nações Unidas para a Educação, a Ciência e a Cultura (UNESCO) (2010); Estados Unidos da América (EUA) (2010) e cálculos deste estudo.

A Índia, com um fator multiplicativo de 32, seria o país com maiores desafios educacionais, em seguida a China, com o fator de 8,9, o Brasil, com 8,3, e a Turquia, com 6,5. A Hungria, com fator multiplicativo de 2,1, e a Rússia, com 3, estariam mais próximos de conseguir aplicar US\$/PPP 7.950,98 por pessoa em idade educacional - média do "bloco" OCDE. A África do Sul, com fator multiplicativo de 5,3, e o México, com 4,1, estariam longe de alcançar o valor médio do "bloco" OCDE. Esses países teriam de aplicar recursos financeiros em percentuais muito elevados do PIB; o Brasil precisaria aplicar 33,2\%, a África do Sul, 28,6\% e o México, 9,68\%, para que alcançassem os valores médios do "bloco" OCDE. Pode-se 
considerar que são percentuais inaplicáveis, levando-se em conta as carências desses países em outros setores sociais.

A relação percentual entre a população em idade educacional e a população total do país pode dar também uma indicação das dificuldades para se solucionar os seus problemas educacionais. O Quadro 2 apresenta essa relação para os países em estudo.

Quadro 2 - População em idade educacional em relação à população do país

\begin{tabular}{|l|c|c|c|}
\hline \multicolumn{1}{|c|}{ País } & $\begin{array}{c}\text { População do país } \\
\text { (A) }\end{array}$ & $\begin{array}{c}\text { População em idade educacional } \\
\text { (B) }\end{array}$ & $\begin{array}{c}\text { B/A } \\
\text { (\%) }\end{array}$ \\
\hline Brasil & 189.000 .000 & 84.400 .000 & 45,0 \\
\hline "Bloco" OCDE & 1.250 .451 .497 & 257.833 .181 & 20,6 \\
\hline Rússia & 138.082 .178 & 35.043 .319 & 25,4 \\
\hline Índia & 1.205 .073 .612 & 557.261 .930 & 46,2 \\
\hline China & 1.343 .239 .923 & 415.339 .912 & 30,9 \\
\hline África do Sul & 48.810 .427 & 20.105 .821 & 41,2 \\
\hline Chile & 17.067 .369 & 5.380 .607 & 31,5 \\
\hline Hungria & 9.958 .453 & 2.661 .708 & 26,7 \\
\hline México & 114.975 .406 & 41.354 .774 & 36,0 \\
\hline Turquia & 79.749 .461 & 24.266 .277 & 30,4 \\
\hline
\end{tabular}

Fonte: UNESCO (2010); EUA (2010) e cálculos deste estudo.

Com exceção da Rússia, com 25,4\% de sua população em idade educacional, e da Hungria, com 26,7\%, e dos países do "bloco" OCDE, com o percentual médio de 20,6\%, todos os demais países apresentam percentuais mais elevados, acima de 30\%: a Índia chega a 46,2\%, o Brasil a 45,0\%, a África do Sul a 41,2\% e o México a $36 \%$, o que nos permite afirmar, comparando com o "bloco" OCDE, que os desafios educacionais para esses países são muito maiores que os dos países do "bloco" OCDE.

A dinâmica populacional brasileira mudará substancialmente esse percentual até o ano de 2050 (Brasil, 2010a), alterando esse elevado percentual do Brasil. O Quadro 3 mostra a projeção do percentual da população em idade educacional.

Quadro 3 - Percentual da população brasileira em idade educacional

\begin{tabular}{|c|c|c|c|}
\hline Ano & $\begin{array}{c}\text { População brasileira } \\
\text { (milhões) (A) }\end{array}$ & $\begin{array}{c}\text { População em idade educacional } \\
\text { (O a 24 anos) (B) }\end{array}$ & $\begin{array}{c}\text { B/A } \\
\text { (\%) }\end{array}$ \\
\hline 2011 & 194,9 & 82,3 & 42,2 \\
\hline 2020 & 207,1 & 75,4 & 36,4 \\
\hline 2030 & 216,4 & 65,4 & 30,2 \\
\hline 2040 & 219,1 & 57,6 & 26,3 \\
\hline 2050 & 215,3 & 50,9 & 23,6 \\
\hline
\end{tabular}

Fonte: Brasil (s.d.) e cálculos deste estudo. 
Esse processo permitirá, portanto, que o Brasil possua um perfil populacional em que os problemas educacionais fiquem mais fáceis de serem solucionados, pois atingirá, a partir de 2040, valores abaixo dos 30\%, aproximando-se dos valores percentuais dos países do "bloco" OCDE.

\section{A PRIVATIZAÇÃO E AS TAXAS LÍQUIDA E BRUTA DA EDUCAÇÃO SUPERIOR BRASILEIRA}

O Censo Demográfico de 2010 apresentou o Brasil com uma população total de 190.757.799 habitantes; desses, 23.878.190 são jovens com idade entre 18 e 24 anos e que estariam, portanto, na idade adequada para realizar um curso de graduação. Entretanto, o Censo da Educação Superior relativo ao ano de 2011 informa-nos que estão matriculados 6.739.689 estudantes - adicionando-se alunos de cursos presenciais e a distância -, sendo que apenas 3.411 .050 estão com idade de 18 a 24 anos. Temos, portanto, uma taxa líquida de $14,3 \%$ e uma taxa bruta de $28,2 \%$.

Segundo classificação internacional, a educação superior ainda é considerada elitista, por possuir um taxa líquida inferior a $15 \%$, limite que, alcançado, deixa essa classificação e se dirige à massificação, o que ocorre ao atingir os 30\%. A educação superior é considerada universalizada quando atinge 50\% de taxa líquida (Gomes; Moraes, 2012).

A educação superior brasileira é altamente privatizada, pois, das 6.739 .689 matrículas em 2011,1.773.315 (26,3\%) realizaram-se em IES públicas e 4.966 .374 $(73,7 \%)$ em IES privadas. Para examinarmos o tamanho dos desafios brasileiros relativos à taxa bruta e à privatização, vamos comparar os dados do Brasil com os valores médios do "bloco" OCDE, do BRICS e do Chile, Hungria, México e Turquia. O Quadro 4 apresenta essas informações. Definimos o fator de multiplicação para atingir a taxa bruta da OCDE para relativizar a "distância" existente entre os diversos países analisados e a média do "bloco" OCDE.

A taxa bruta da Índia é de $16 \%$, do México é de 26\%, da China é de $28 \%$ e do Brasil é de $28,2 \%$. Para atingir os elevados percentuais já alcançados pelos países do "bloco" OCDE, Rússia, Hungria e Chile, os outros países terão de realizar uma grande expansão de seus sistemas terciários: a Índia possui um fator multiplicativo de 4,2, o México de 2,6, a China e o Brasil de 2,4 e a Turquia de 1,5.

Conclui-se que o Brasil terá ainda de aumentar muito o quantitativo de jovens matriculados na educação superior, tanto pública quanto privada. Há, entretanto, como já vimos, uma alteração na dinâmica de crescimento da quantidade de pessoas, o que levará a uma estabilização no total da população, com uma forte diminuição no número de crianças e jovens em idade educacional ( 0 a 24 anos). O Quadro 5 mostra o resultado de um estudo do Instituto Brasileiro de Geografia e Estatística (IBGE) que projetou a evolução desse quantitativo até 2050.

Haverá, portanto, uma elevação da população de 194,9 milhões, em 2011, para 219,1 milhões em 2040, e já em 2050 a população terá diminuído para 215,3 milhões de pessoas. A população em idade educacional diminuirá em $38 \%$ e o número de jovens com idade entre 18 e 24 anos sofrerá uma redução de 23,5 milhões para 16,1 milhões. 
Quadro 4 - Privatização, taxa bruta e fator de multiplicação para atingir a taxa bruta do "bloco" OCDE

\begin{tabular}{|l|c|c|c|}
\hline \multicolumn{1}{|c|}{ País } & $\begin{array}{c}\text { Percentual de privatização } \\
\text { da educação superior (\%) }\end{array}$ & $\begin{array}{c}\text { Taxa Bruta } \\
(\%)\end{array}$ & $\begin{array}{c}\text { Fator de multiplicação para } \\
\text { atingir a taxa bruta do "bloco" } \\
\text { OCDE }\end{array}$ \\
\hline Brasil & 73,7 & 28,2 & 2,4 \\
\hline "Bloco" OCDE & 5 & 67 & 1,0 \\
\hline Rússia & 15 & 76 & 0,9 \\
\hline Índia & - & 16 & 4,2 \\
\hline China & - & 28 & 2,4 \\
\hline África do Sul & - & - & - \\
\hline Chile & 80 & 58 & 1,2 \\
\hline Hungria & 16 & 66 & 1,0 \\
\hline México & 33 & 26 & 2,6 \\
\hline Turquia & 6 & 46 & 1,5 \\
\hline
\end{tabular}

Fonte: Brasil (2011a); UNESCO (2010) e OCDE (2011).

Quadro 5 - Dinâmica populacional em idade educacional até 2050 (em milhões)

\begin{tabular}{|l|r|r|r|r|r|c|}
\hline \multicolumn{1}{|c|}{ Nível/Etapa da educação } & $\mathbf{2 0 1 1}$ & $\mathbf{2 0 2 0}$ & $\mathbf{2 0 3 0}$ & $\mathbf{2 0 4 0}$ & $\mathbf{2 0 5 0}$ & $\begin{array}{c}\text { Variação \% } \\
\text { (2011-2050) }\end{array}$ \\
\hline Creche & 11,8 & 10,1 & 9,3 & 8,0 & 7,1 & -40 \\
\hline Educação infantil (4 a 5 anos) & 6,4 & 5,2 & 4,8 & 4,2 & 3,7 & -42 \\
\hline Ensino fundamental & 30,7 & 26,2 & 22,6 & 20,5 & 17,6 & -43 \\
\hline Ensino médio & 9,9 & 10,1 & 7,9 & 7,3 & 6,4 & -35 \\
\hline Educação superior & 23,5 & 23,8 & 20,8 & 17,6 & 16,1 & -31 \\
\hline Total da população em idade educacional & 82,3 & 75,4 & 65,4 & 57,6 & 50,9 & -38 \\
\hline População total do Brasil & $\mathbf{1 9 4 , 9}$ & $\mathbf{2 0 7 , 1}$ & $\mathbf{2 1 6 , 4}$ & $\mathbf{2 1 9 , 1}$ & $\mathbf{2 1 5 , 3}$ & $+\mathbf{+ 1 1}$ \\
\hline
\end{tabular}

Fonte: Brasil (2008).

Deve-se ressaltar que essa dinâmica populacional colaborará para que o Brasil eleve a taxa bruta na educação superior. $O$ Quadro 6 apresenta a projeção para o quantitativo de estudantes matriculados nesse período, para atingirmos a taxa bruta de $50 \%$.

O quadro mostra ainda a diminuição da dificuldade para o Brasil vencer esse desafio; em relação aos estudantes efetivamente matriculados em 2011 (6.739.689), há uma drástica queda na necessidade de expansão, de 77,1\% em 2011 para 12,0\% em 2050.

Entretanto, não devemos esquecer que os desafios relativos à saúde dos idosos e ao pagamento de previdência social serão gradativamente elevados. O Quadro 7 apresenta a evolução percentual da população brasileira com idade a partir de 61 anos, nesse mesmo período. 
Quadro 6 - Projeção no número de matriculados para taxa bruta de 50\% no Brasil

\begin{tabular}{|c|c|c|c|}
\hline Ano & $\begin{array}{c}\text { Número de jovens com } \\
\text { idade de 18 a 24 anos }\end{array}$ & $\begin{array}{c}\text { Número de matrículas na } \\
\text { educação superior para } \\
\text { taxa bruta de 50\% }\end{array}$ & $\begin{array}{c}\text { Crescimento em relação do } \\
\text { total de 2011 (6.739.689) }\end{array}$ \\
\hline 2011 & 23.878 .190 & 11.939 .095 & $77,1 \%$ \\
\hline 2020 & 23.754 .743 & 11.877 .372 & $76,2 \%$ \\
\hline 2030 & 20.772 .452 & 10.386 .226 & $54,1 \%$ \\
\hline 2040 & 17.582 .673 & 8.791 .337 & $30,4 \%$ \\
\hline 2050 & 16.120 .983 & 8.060 .492 & $12,0 \%$ \\
\hline
\end{tabular}

Fonte: Brasil (2008).

Quadro 7 - Percentual da população com idade a partir de 61 anos (2011-2050)

\begin{tabular}{|c|c|c|c|}
\hline Ano & População brasileira (A) & População com idade a partir de 61 anos (B) & B/A (\%) \\
\hline 2011 & 194.932 .685 & 18.570 .421 & 9,5 \\
\hline 2020 & 207.143 .243 & 28.321 .799 & 13,7 \\
\hline 2030 & 216.410 .030 & 38.061 .298 & 17,6 \\
\hline 2040 & 219.075 .130 & 49.123 .402 & 22,4 \\
\hline 2050 & 215.287 .463 & 61.036 .746 & 28,4 \\
\hline
\end{tabular}

Fonte: Brasil (2008).

A população brasileira chegará, portanto, a 2050 com $28,4 \%$ de sua população com idade a partir de 61 anos, uma evolução percentual que as políticas a serem colocados em prática com os recursos do fundo público precisam considerar.

$\mathrm{Na}$ próxima década, há a necessidade de expandir a educação superior, o que se deve realizar tanto nas esferas públicas quanto privadas. Entretanto, as desigualdades brasileiras impedem que exista a expansão sem o aporte de substancial volume de recursos públicos, como veremos a seguir.

\section{O LIMITE SOCIOECONÔMICO PARA A EXPANSÃO DA EDUCAÇÃO SUPERIOR BRASILEIRA}

Analisando a quantidade de vagas que ficaram sem preenchimento nas IES e as relações candidatos/vagas oferecidas em três momentos - em 1995, primeiro ano do governo de Fernando Henrique Cardoso; 2005, último ano do primeiro mandato de Luiz Inácio Lula da Silva; e 2011, segundo ano do governo de Dilma Rousseff -, podemos dizer que há indícios de que a população brasileira está atingindo um limite no qual não é mais possível às famílias financiarem uma educação superior para os seus jovens - tanto em IES públicas quanto privadas -, uma vez que a frequência a um curso de graduação, independentemente da gratuidade ou não da instituição, possui um custo elevado, que se relaciona a transporte, alimentação, aquisição de material para o curso, cópias, vida cultural, entre outros. 
A separação de datas proposta justifica-se pelo fato de que no período 1995-2005 houve uma grande expansão do setor privado (213,6\%), que teve continuidade no período 2005-2011 (49,5\%), mas no qual também houve uma expansão do setor público de $42,2 \%$, não tão distante da expansão privada. $\mathrm{O}$ Quadro 8 apresenta os dados dessa expansão.

Quadro 8 - Percentual de variação de matrículas nos três períodos em destaque (1995-2011)

\begin{tabular}{|l|r|r|c|c|c|}
\hline \multicolumn{1}{|c|}{ Ano } & Federais & Estaduais & Municipais & Total Públicas & Privadas \\
\hline 1995 & 367.531 & 239.215 & 93.794 & 700.540 & 1.059 .163 \\
\hline 2005 & 595.327 & 514.726 & 136.651 & 1.246 .704 & 3.321 .094 \\
\hline 2011 & 1.032 .936 & 619.354 & 121.025 & 1.773 .315 & 4.966 .374 \\
\hline$(1995-2005) \%$ & 62,0 & 151,7 & 45,7 & 78,0 & 213,6 \\
\hline$(2005-2011) \%$ & 73,5 & 20,3 & $-11,4$ & 42,2 & 49,5 \\
\hline
\end{tabular}

Fonte: Brasil (2011a).

Como vimos, a educação superior brasileira ainda é elitista e a taxa bruta ainda precisa crescer muito. Entretanto, o Quadro 9 mostra nesses três períodos como se comportaram o quantitativo de vagas não preenchidas e a relação candidatos/vagas oferecidas em cursos presenciais.

Quadro 9 - Percentual de variação de matrículas nos três períodos em destaque (1995-2011)

\begin{tabular}{|c|c|c|c|c|}
\hline \multirow{2}{*}{ Ano } & \multicolumn{2}{|c|}{ IES públicas } & \multicolumn{2}{c|}{ IES privadas } \\
\cline { 2 - 5 } & $\begin{array}{c}\text { Vagas não } \\
\text { preenchidas (\%) }\end{array}$ & $\begin{array}{c}\text { Relação candidatos/ } \\
\text { vagas }\end{array}$ & $\begin{array}{c}\text { Vagas não } \\
\text { preenchidas (\%) }\end{array}$ & $\begin{array}{c}\text { Relação candidatos/ } \\
\text { vagas }\end{array}$ \\
\hline 1995 & 11,3 & 7,9 & 18,5 & 2,9 \\
\hline 2005 & 7,9 & 7,4 & 47,8 & 1,3 \\
\hline 2011 & 12,0 & 10,6 & 54,1 & 1,5 \\
\hline
\end{tabular}

Fonte: Brasil (2011a).

Chama atenção o grande aumento no percentual de vagas não preenchidas nas IES privadas, partindo de 18,5\% em 1995 para 54,1\% em 2011 e a grande queda na relação candidatos/vagas, que era 2,9 em 1995 e em 2011 foi de 1,5. São dois movimentos que sinalizam a impossibilidade das famílias brasileiras de efetuarem suas matrículas nas IES privadas. Em contrapartida, era de esperar que houvesse uma grande elevação na relação candidatos/vagas nas IES públicas, considerando o aumento de vagas oferecidas e também a introdução, sobretudo nas IES federais, dos programas de inclusão, o que não ocorreu, sinalizando também uma impossibilidade de as famílias manterem seus jovens em uma IES pública.

Examinando o perfil socioeconômico da população, podemos verificar que existe um limite à quantidade de famílias que podem manter seus jovens realizando um curso de graduação. $\mathrm{O}$ Quadro 10 apresenta a quantidade de moradores em 
domicílios particulares por classe de rendimento mensal domiciliar per capita, em salários mínimos.

Quadro 10-Moradores em domicílios particulares por classe de rendimento mensal

\begin{tabular}{|l|c|c|c|}
\hline $\begin{array}{c}\text { Classes de rendimento } \\
\text { nominal mensal domiciliar per } \\
\text { capita (salário mínimo) }\end{array}$ & $\begin{array}{c}\text { Moradores em } \\
\text { domicílios particulares } \\
\text { permanentes }\end{array}$ & $\%$ & $\begin{array}{c}\text { Média de moradores em } \\
\text { domicílios particulares } \\
\text { permanentes }\end{array}$ \\
\hline Até $1 / 8$ & 10.232 .325 & 5,4 & 4,9 \\
\hline Mais de $1 / 8$ a $1 / 4$ & 18.351 .811 & 9,7 & 4,7 \\
\hline Mais de $1 / 4$ a $1 / 2$ & 38.551 .353 & 20,4 & 3,9 \\
\hline Mais de $1 / 2$ a 1 & 52.657 .183 & 27,8 & 3,2 \\
\hline Mais de 1 a 2 & 36.912 .697 & 19,5 & 2,9 \\
\hline Mais de 2 a 3 & 11.033 .158 & 5,8 & 2,7 \\
\hline Mais de 3 a 5 & 8.001 .625 & 4,2 & 2,6 \\
\hline Mais de 5 a 10 & 4.999 .887 & 2,6 & 2,1 \\
\hline Mais de 10 & 1.837 .032 & 1,0 & 2,8 \\
\hline Sem rendimentos & 6.824 .313 & 3,6 & 3,3 \\
\hline Total & $\mathbf{1 8 9 . 4 0 1 . 3 8 4}$ & $\mathbf{1 0 0}$ & \\
\hline
\end{tabular}

Fonte: Brasil (2010b).

Quadro 11 - Quantidade de pessoas que poderiam pagar mensalidades na educação superior, por faixa etária

\begin{tabular}{|l|r|r|r|c|}
\hline \multirow{2}{*}{$\begin{array}{c}\text { Renda domiciliar per capita } \\
\text { (salário mínimo) }\end{array}$} & \multicolumn{4}{|c|}{ Idades } \\
\cline { 2 - 5 } & 18 e 19 & 20 a 24 & 25 a 29 & Total \\
\hline Mais de 2 a 3 & 301.432 & 1.045 .317 & 1.194 .314 & 2.541 .063 \\
\hline Mais de 3 a 5 & 183.241 & 641.314 & 864.461 & 1.689 .016 \\
\hline Mais de 5 & 119.334 & 405.254 & 667.042 & 1.191 .630 \\
\hline Total & $\mathbf{6 0 4 . 0 0 7}$ & 2.091 .885 & 2.725 .817 & 5.421 .709 \\
\hline
\end{tabular}

Fonte: Brasil (2010b).

Conforme dados do Instituto de Pesquisa Econômica Aplicada (IPEA), verifica-se que grande parte dos habitantes vive em famílias consideradas extremamente pobres (até $1 / 8$ salário mínimo per capita), pobres (mais de 1/8 a 1/4 salário mínimo per capita) ou vulneráveis (mais de $1 / 4$ a 1 salário mínimo per capita) (Brasil, 2011b), e são exatamente essas famílias que possuem os maiores números de moradores por domicílio.

Neste estudo, consideraremos que só conseguem estudar na educação superior, tanto em instituições públicas quanto privadas, aquelas pessoas que residem em domicílios com renda per capita a partir de dois salários mínimos. Essas pessoas teriam condições de custear transporte, alimentação, aquisição de material para o curso, livros, 
fotocópias, vida cultural etc. A quantidade de pessoas que reside nessas famílias nas faixas etárias de 18 e 19 anos, 20 a 24 e 25 a 29 anos está apresentada no Quadro 11.

$\mathrm{Na}$ educação superior, no ano de 2011, estavam matriculados 6.739.299 alunos, de todas as idades, com 4.813.301 possuindo idade entre 18 e 29 anos (Brasil, 2011a). Podemos considerar que entre os 5.421 .709 jovens com idade de 18 a 29 anos que poderiam realizar um curso de graduação já se encontravam os 4.813.301 então matriculados, o que nos permite afirmar que há um limite próximo à expansão do setor privado, e também do setor público, em virtude do perfil socioeconômico da população.

Portanto, o caminho para a ampliação das matrículas em todos os níveis educacionais é complexo, e os desafios para a elevação dos patamares de qualidade exigem mudanças significativas na estrutura socioeconômica da população, além da aplicação de recursos financeiros públicos em educação, em todos os seus níveis, etapas e modalidades, que precisam dirigir-se também para ações que permitam a permanência dos estudantes na IES.

O Brasil encontra-se, portanto, em uma encruzilhada no que diz respeito ao financiamento da educação superior, já que, atingido o limite para expansão, há que se elevar o volume de recursos financeiros a ser aplicado nas IES públicas, tanto federais quanto estaduais e municipais, sendo que estas possuem a especificidade de fundações municipais, que cobram mensalidades. Para que isso ocorra, será preciso elevar os recursos financeiros aplicados na educação brasileira, o que está em discussão no Congresso Nacional, para o estabelecimento de um novo PNE.

\section{O FINANCIAMENTO DA EDUCAÇÃO SUPERIOR NO NOVO PNE}

O projeto de lei n. 8.035/2010 estabeleceu as seguintes propostas de metas que diretamente se relacionam com a educação superior:

Meta 12 - Elevar a taxa bruta de matrícula na educação superior para $50 \%$ e a taxa líquida para $33 \%$ da população de 18 a 24 anos, assegurando a qualidade da oferta.

Meta 13 - Elevar a qualidade da educação superior pela ampliação de mestres e doutores nas instituições de educação superior para 75\%, no mínimo, do corpo docente em efetivo exercício, sendo, do total, $35 \%$ doutores.

Meta 14 - Elevar gradualmente o número de matrículas na pós-graduação stricto sensu de modo a atingir a titulação anual de 60 mil mestres e 25 mil doutores. (Brasil, 2010a, p. 31 e 35)

Especificamente sobre a meta 12, o Ministério da Educação (MEC), em notas técnicas (Brasil, 2011c) encaminhadas à Câmara dos Deputados, considerou no final da década do novo plano as seguintes condições para projetar o financiamento associado à expansão: a relação de matrículas públicas-privadas seria de 26,4\% públicas e $73,6 \%$ privadas; $50 \%$ das matrículas expandidas na esfera pública seriam em cursos presenciais e $50 \%$ em cursos oferecidos na educação a distância $(\mathrm{EaD})$; e o custo aluno/ano do estudante em cursos $\mathrm{EaD}$ seria $20 \%$ do aluno em cursos 
presenciais. Além disso, em suas considerações o MEC estimou que deveríamos passar de um total de 5.905.021 estudantes em 2009 para um total de 11.517 .600 estudantes em 2020, ou seja, um aumento de 93,4\% (o MEC considerou que o período do novo PNE seria 2011-2020). As metas 13 e 14 referem-se a aspectos relacionados à elevação da qualidade da educação superior e da matrícula na pós-graduação stricto sensu.

$\mathrm{O}$ fato de a proposta contida nas notas técnicas indicar a permanência da relação de matrículas públicas e privadas existente em 2009 implica manter o Brasil na lista dos países com um dos maiores percentuais de matrículas em instituições privadas de educação superior, como já vimos. Ao propor que no Brasil, em 2020, o percentual público seja de $26,4 \%$ e o percentual privado de $73,6 \%$, o governo federal não planeja, portanto, alterar esta incômoda situação de elevados percentuais de matrículas privadas.

Se em 2020, conforme a proposta apresentada pelo governo federal, deveríamos ter 11.517 .160 pessoas matriculadas na educação superior, isso significa que deveríamos ter no setor privado um total de 8.476 .630 estudantes, o que representa a incorporação de mais 4.946.243; temos, portanto, de praticamente dobrar o tamanho do setor privado. A menos que nesse período haja uma grande mudança no perfil socioeconômico da população brasileira, é certo que não existirão tantas novas famílias em condições de efetivar o pagamento de mensalidades, como já vimos.

A expansão do setor público, nesse caso, deveria incorporar um total de 1.523.634 novos estudantes - o que significaria, também, praticamente dobrar a educação superior pública. Dessas matrículas novas, o MEC propõe ainda que a metade delas, 761.817, seja em cursos oferecidos a distância, a um custo de $20 \%$ do custo da matrícula presencial.

O quantitativo de matrículas em cursos oferecidos a distância é ainda baixo no Brasil; eram apenas 838.125 matrículas em $2009,14,1 \%$ do total, sendo que nas IES públicas são apenas $86.550,1,4 \%$ do total. A experiência brasileira no ensino de graduação a distância é ainda pequena e a expansão deve ser mais bem controlada; saltar de 85.550 para 848.367 , um crescimento de $880 \%$, é uma tarefa de grande risco quanto à qualidade dos cursos oferecidos. Além disso, os recursos financeiros associados às matrículas em $\mathrm{EaD}$ não podem, principalmente no início do processo, ser tão baixo, apenas 20\% do presencial.

Essas condições restritivas estabelecidas pelo governo federal estão associadas ao patamar estabelecido na meta 20 do projeto de lei n. 8.035, de aplicar em educação no ano 2020 recursos financeiros equivalentes a $7 \%$ do PIB, sendo que diversas simulações indicam que o percentual que viabilizaria os princípios, os objetivos e as metas do PNE 2011-2020 seria de 10\% do PIB (Amaral, 2011; Pinto, 2011).

Considerando que o volume total de recursos financeiros aplicados em educação em 2020 esteja no patamar de 10\% do PIB, podemos adotar medidas menos restritivas que as do governo federal e que promovam uma expansão da educação superior com melhores condições para que ela seja exequível e com melhor qualidade. Dessa forma, consideraremos neste estudo que a expansão alterará os percentuais existentes para $40 \%$ no setor público e $60 \%$ no setor privado - retomando uma meta aprovada no PNE 2001-2010 e vetada pelo Executivo; que os cursos a 
distância correspondam a $25 \%$ das matrículas expandidas e que os recursos associados à matrícula em cursos a distância sejam $60 \%$ daquele recurso associado à matrícula presencial.

Dessa forma, deveríamos chegar em 2020 com 11.517 .160 pessoas matriculadas na educação superior, sendo 4.606 .864 matriculados na educação superior pública e 6.910.296 na educação superior privada. Em 2009, são 1.523.634 e 4.430.387, respectivamente. O Quadro 12 mostra os quantitativos de estudantes presenciais e a distância, em cada uma das esferas administrativas, para que em 2020 tenhamos $75 \%$ da expansão em cursos presenciais e $25 \%$ da expansão em cursos a distância.

Quadro 12 - Número de matrículas em 2020 na visão dos $10 \%$ do PIB

\begin{tabular}{|l|c|r|r|r|}
\hline \multirow{2}{*}{ IES } & \multicolumn{2}{|c|}{2009} & \multicolumn{2}{c|}{2020} \\
\cline { 2 - 5 } & $\begin{array}{l}\text { Matrículas } \\
\text { presenciais }\end{array}$ & $\begin{array}{l}\text { Matrículas } \\
\text { a distância }\end{array}$ & $\begin{array}{l}\text { Matrículas } \\
\text { presenciais }\end{array}$ & $\begin{array}{l}\text { Matrículas } \\
\text { a distância }\end{array}$ \\
\hline Federais & 752.847 & 86.550 & 2.041 .192 & 472.827 \\
\hline Estaduais & 480.145 & 86.059 & 1.301 .816 & 470.144 \\
\hline Municipais & 118.176 & 87 & 320.410 & 475 \\
\hline Particulares & 2.899 .763 & 527.838 & 4.332 .499 & 1.019 .668 \\
\hline $\begin{array}{l}\text { Comunitárias/Confessionais/ } \\
\text { Filantrópicas }\end{array}$ & 864.965 & 137.591 & 1.292 .333 & 265.796 \\
\hline Total & 5.115 .896 & 838.125 & 9.288 .250 & 2.228 .910 \\
\hline
\end{tabular}

Fonte: Brasil (2009b) e cálculos deste estudo.

Chegaríamos em 2020 com 9.288.250 alunos matriculados nos cursos presenciais e 2.228.910 matriculados na $\mathrm{EaD}$, ou seja, uma elevação de $82 \%$ e $166 \%$, respectivamente. O Quadro 13 mostra as expansões percentuais que cada uma das esferas administrativas deveria realizar nas matrículas presenciais e em EaD.

Quadro 13 - Percentuais de expansão para cada esfera administrativa, de 2009 para 2020

\begin{tabular}{|l|c|c|}
\hline \multirow{2}{*}{ IES } & \multicolumn{2}{|c|}{ 2009/2020 } \\
\cline { 2 - 3 } & Matrículas presenciais (\%) & Matrículas a distância (\%) \\
\hline Federais & 171 & 446 \\
\hline Estaduais & 171 & 446 \\
\hline Municipais & 171 & 446 \\
\hline Particulares & 49 & 93 \\
\hline Comunitárias/Confessionais/ & 49 & 93 \\
\hline Filantrópicas & & $\mathbf{1 6 6}$ \\
\hline Total & 82 & \multicolumn{2}{|c|}{} \\
\hline
\end{tabular}

Fonte: Brasil (2009b) e cálculos deste estudo. 
As públicas precisarão elevar suas matrículas presenciais e a distância em $171 \%$ e $49 \%$ e as IES privadas, 149\% e 93\%, respectivamente.

Para calcular o valor total de recursos financeiros a serem aplicados em 2020, consideraremos que serão aqueles apresentados pelo Censo da Educação Superior de 2005, corrigidos pelo Índice Nacional de Preços ao Consumidor Amplo (IPCA) para janeiro de 2011. O Quadro 14 mostra esses valores.

\section{Quadro 14 - Despesas realizadas pelas IES brasileiras em 2005 como percentuais do PIB}

(Valores em R\$ bilhões, a preços de janeiro de 2010, corrigidos pelo IPCA)

\begin{tabular}{|l|c|c|}
\hline \multicolumn{1}{|c|}{ Esfera administrativa } & Despesas & PIB (\%) \\
\hline Federal & 19,17 & 0,70 \\
\hline Estadual & 9,65 & 0,35 \\
\hline Municipal & 1,51 & 0,05 \\
\hline Total & $\mathbf{3 0 , 3 3}$ & $\mathbf{1 , 1 0}$ \\
\hline Particulares & 15,32 & 0,56 \\
\hline Comunitárias/Confessionais/Filantrópicas & 15,94 & 0,58 \\
\hline Total & $\mathbf{3 1 , 2 6}$ & $\mathbf{1 , 1 4}$ \\
\hline Total geral & $\mathbf{6 1 , 5 9}$ & $\mathbf{2 , 2 4}$ \\
\hline
\end{tabular}

Fonte: Brasil (2005) e cálculos deste estudo.

Esses recursos financiaram os quantitativos de alunos do Quadro 15, sendo que em 2005 o quantitativo de matrículas presenciais atingiu o total de 4.453.156 e a distância, 127.014 .

Quadro 15 - Número de matrículas em 2005

\begin{tabular}{|l|c|c|}
\hline \multicolumn{1}{|c|}{ Esfera administrativa } & Matrículas presenciais & Matrículas a distância \\
\hline Federal & 579.587 & 15.676 \\
\hline Estadual & 477.349 & 37.377 \\
\hline Municipal & 135.253 & 0 \\
\hline $\begin{array}{l}\text { Particular + Comunitária/ } \\
\text { Confessional/Filantrópica }\end{array}$ & 3.260 .967 & 73.961 \\
\hline Total & 4.453 .156 & $\mathbf{1 2 7 . 0 1 4}$ \\
\hline
\end{tabular}

Fonte: Brasil (2005).

Nota-se no Quadro 15 que o quantitativo de matrículas em $\mathrm{EaD}$ no ano de 2005 era pequeno; o crescimento de 2005 para 2009 foi de $560 \%$. Um crescimento muito rápido e que necessita ainda adquirir uma estabilidade no que se relaciona a aspectos de qualidade da formação dos alunos e de ação institucional dirigida a essa forma de oferecimento da educação superior.

Com as informações dos Quadros 14 e 15 podemos obter o valor aplicado por aluno no ano de 2005 , considerando que esse valor para a $\mathrm{EaD}$ é de $60 \%$ do aplicado por aluno nos cursos presenciais. O Quadro 16 mostra o resultado. 
Quadro 16 - Valor aplicado por aluno em 2005

(Valores em R\$ a preços de janeiro de 2011, corrigidos pelo IPCA)

\begin{tabular}{|l|c|c|}
\hline \multirow{2}{*}{ Esfera administrativa } & \multicolumn{2}{|c|}{2005} \\
\cline { 2 - 3 } & $\begin{array}{c}\text { Valor por aluno em } \\
\text { cursos presenciais }\end{array}$ & $\begin{array}{c}\text { Valor por aluno em cursos a } \\
\text { distância (60\% dos presenciais) }\end{array}$ \\
\hline Federal & 32.547 & 19.528 \\
\hline Estadual & 19.309 & 11.585 \\
\hline Municipal & 11.164 & 6.699 \\
\hline $\begin{array}{l}\text { Particular + Comunitária/ } \\
\text { Confessional/Filantrópica }\end{array}$ & 9.457 & 5.674 \\
\hline
\end{tabular}

Fonte: Amaral e Pinto (2010, p. 68).

Ressalte-se que estão incluídas nesses valores aplicados por aluno todas as despesas realizadas nas instituições: pagamento de pessoal ativo; pagamento de aposentados e pensionistas; pagamento de água, luz, telefone, vigilância, limpeza, material de consumo, reformas de prédios; manutenção dos hospitais universitários, orquestras, fazendas, corais, rádios, televisores; construção de prédios, aquisição de equipamentos etc. Isso significa que os valores do Quadro 16 não podem ser interpretados como custo do aluno de graduação das instituições, que deve retirar, entre outros, o pagamento de aposentados e pensionistas e parte dos recursos dos hospitais universitários. O cálculo do custo do aluno de graduação utilizando os dados financeiros de 2005 foi realizado por Amaral e Pinto (2010, p. 68).

Utilizando os valores por aluno do Quadro 16 e as matrículas em 2020 do Quadro 12, seria necessário que o Brasil aplicasse de recursos públicos e privados - das famílias - um total de $\mathrm{R} \$ 156,7$ bilhões na educação superior, sendo que projeções do Ministério da Fazenda (Brasil, 2009a) mostram que o PIB brasileiro em 2020 deverá atingir o valor de $\mathrm{R} \$ 4,21$ trilhões; dessa forma, esses $\mathrm{R} \$ 156,7$ bilhões significariam, em 2020, 3,72\% do PIB, sendo que os recursos públicos federais seriam $1,80 \%$ do PIB, os estaduais $0,72 \%$, os municipais $0,09 \%$ e os privados $1,11 \%$ do PIB. O Quadro 17 apresenta esses percentuais, comparando-os com os percentuais aplicados em 2005.

Quadro 17 - Percentual do PIB aplicado em 2005 e a ser aplicado em 2020

\begin{tabular}{|l|c|c|}
\hline \multicolumn{1}{|c|}{ Esfera administrativa } & $\mathbf{2 0 0 5}(\boldsymbol{\%})$ & $\mathbf{2 0 2 0}(\mathbf{\%})$ \\
\hline Federal & 0,70 & 1,80 \\
\hline Estadual & 0,35 & 0,72 \\
\hline Municipal & 0,05 & 0,09 \\
\hline Particular + Comunitária/Confessional/Filantrópica & 1,14 & 1,11 \\
\hline Total & $\mathbf{2 , 2 4}$ & $\mathbf{3 , 7 2}$ \\
\hline
\end{tabular}

Fonte: Amaral e Pinto (2010, p. 68). 
Os recursos federais precisariam sofrer a maior elevação como percentual do $\mathrm{PIB}$, de $0,70 \%$ para $1,80 \%$. A esfera privada deverá continuar aplicando em torno de $1,10 \%$ do PIB, e as esferas estaduais e municipais teriam de praticamente dobrar os seus percentuais em relação ao PIB.

Portanto, dos recursos totais - supondo a aprovação dos 10\% do PIB -, 2,61\% deveriam dirigir-se à educação superior pública, para que tivéssemos uma taxa bruta de $50 \%$ e uma taxa líquida de $33 \%$.

\section{CONSIDERAÇÕES FINAIS: O BRASIL E OS RECURSOS APLICADOS EM EDUCAÇÃO SUPERIOR EM OUTROS PAÍSES}

Se o Brasil passar a aplicar em educação um volume de recursos equivalente a 10\% do PIB, e chegar em 2020 aplicando 2,61\% do PIB em educação superior, terá um percentual que pode ser comparado com aquele investido pelos países da OCDE, que foi de 1,4\% em 2009 (OCDE, 2011). Examinando somente esse indicador, temos a sensação de que o Brasil estaria atribuindo muito mais recursos que os países da OCDE; entretanto, para uma análise mais completa precisaríamos considerar ainda duas outras informações: o valor do PIB do país e o tamanho do alunado a ser atendido, o que pode ser expresso pela quantidade de pessoas do país que estão em idades adequadas para participarem do processo educacional na educação superior. O Quadro 18 apresenta essa análise para diversos países.

O Quadro 18 indica também que, mesmo aplicando o equivalente a 2,61\% do PIB em educação superior, o Brasil ainda ficaria com US\$/PPP 2.293,38, que é um valor pequeno comparado com os países mais ricos. Continuando a aplicar o equivalente a 2,61\% do PIB ao longo das próximas décadas, o Quadro 19 mostra os valores por pessoa em idade educacional até o ano de 2050, utilizando para o crescimento do PIB dados do Ministério da Fazenda (Brasil, 2009a).

Verifica-se que até o ano de 2030 o Brasil já entraria no conjunto de alguns países da OCDE, como a Austrália, Espanha, França e Alemanha; entretanto, somente em 2050 atingiria um valor próximo ao dos Estados Unidos, que foi de US\$/PPP 8.417,33.

Esse nível educacional, pelo papel que desempenha para o desenvolvimento do Brasil, além de necessitar de grande expansão, ainda precisa elevar a sua qualidade. Essa comparação permite-nos afirmar que, se nas próximas décadas o Brasil estiver aplicando o equivalente a 10\% do seu PIB em educação e, desses recursos, 2,61\% na educação de seus jovens de 18 a 24 anos, estaríamos dando um grande passo para implantar uma configuração na educação brasileira que atende a esses jovens de forma adequada, em IES que possam desenvolver suas atividades de ensino, pesquisa e extensão com qualidade, sendo ainda responsáveis por desenvolver novos conhecimentos, novas tecnologias e novos processos de inovação que possam ser incorporados à dinâmica do país, propiciando um melhor desenvolvimento econômico e social. 
Quadro 18 - Recursos financeiros públicos aplicados em educação superior, por pessoa em idade educacional

\begin{tabular}{|l|c|c|c|c|c|}
\hline \multicolumn{1}{|c|}{ País } & $\begin{array}{c}\text { PIB aplicado } \\
\text { em educação } \\
\text { superior (\%) }\end{array}$ & $\begin{array}{c}\text { PIB/PPP } \\
\text { de 2009 } \\
\text { (US\$/PPP } \\
\text { bilhões) }\end{array}$ & $\begin{array}{c}\text { Valor aplicado } \\
\text { em educação } \\
\text { (US\$/PPP } \\
\text { bilhões) }\end{array}$ & $\begin{array}{c}\text { População em } \\
\text { idade educacional } \\
\text { de educação } \\
\text { superior }\end{array}$ & $\begin{array}{c}\text { US\$/PPP por } \\
\text { pessoa em idade } \\
\text { educacional de } \\
\text { educação superior }\end{array}$ \\
\hline Brasil & 2,61 & 2.024 & 52,8 & 23.034 .321 & $2.293,38$ \\
\hline Rússia & 1,2 & 2.103 & 25,2 & 111.929 .016 & 225,46 \\
\hline Índia & 1,3 & 3.548 & 46,1 & 117.642 .131 & 392,07 \\
\hline China & - & 8.767 & - & 12.237 .264 & - \\
\hline $\begin{array}{l}\text { África } \\
\text { do Sul }\end{array}$ & 0,7 & 488 & 3,4 & 5.053 .122 & 676,02 \\
\hline México & 1,1 & 1.473 & 16,2 & 9.648 .392 & $1.679,35$ \\
\hline Argentina & 1,1 & 558 & 6,1 & 3.297 .568 & $1.861,37$ \\
\hline Chile & 1 & 244 & 2,4 & 1.469 .094 & $1.660,89$ \\
\hline Portugal & 1,1 & 232 & 2,6 & 626.228 & $4.075,19$ \\
\hline $\begin{array}{l}\text { Coreia } \\
\text { do Sul }\end{array}$ & 0,9 & 1.343 & 12,1 & 3.266 .647 & $3.700,12$ \\
\hline França & 1,3 & 2.113 & 27,5 & 3.965 .925 & $6.926,25$ \\
\hline Dinamarca & 2,4 & 199 & 4,8 & 295.584 & $16.157,84$ \\
\hline Canadá & 1,8 & 1.278 & 23,0 & 2.226 .706 & $10.330,96$ \\
\hline Espanha & 1,1 & 1.367 & 15,0 & 2.523 .345 & $5.959,15$ \\
\hline Austrália & 1,1 & 819 & 9,0 & 1.451 .761 & $6.205,57$ \\
\hline Alemanha & 1,3 & 2.812 & 36,6 & 4.924 .663 & $7.423,05$ \\
\hline Japão & 0,8 & 4.141 & 33,1 & 6.787 .174 & $4.880,97$ \\
\hline $\begin{array}{l}\text { Estados } \\
\text { Unidos }\end{array}$ & 1,3 & 14.250 & 185,3 & 22.008 .178 & $8.417,33$ \\
\hline Noruega & 2,2 & 277 & 6,1 & 290.564 & $20.973,00$ \\
\hline
\end{tabular}

Fonte: UNESCO (2010); EUA (2010); OCDE (2011) e cálculos deste estudo.

Quadro 19 - Valores aplicados na educação superior pública por pessoa em idade educacional, até 2050

\begin{tabular}{|c|c|c|c|c|c|}
\hline Ano & $\begin{array}{c}\text { PIB } \\
\text { aplicado em } \\
\text { educação } \\
\text { superior (\%) }\end{array}$ & $\begin{array}{c}\text { PIB/PPP } \\
\text { de 2009 } \\
\text { (US\$/PPP } \\
\text { bilhões) }\end{array}$ & $\begin{array}{c}\text { Valor aplicado } \\
\text { em educação } \\
\text { (US\$/PPP } \\
\text { bilhões) }\end{array}$ & $\begin{array}{c}\text { População em idade } \\
\text { educacional de } \\
\text { educação superior }\end{array}$ & $\begin{array}{c}\text { US\$/PPP por } \\
\text { pessoa em idade } \\
\text { educacional de } \\
\text { educação superior }\end{array}$ \\
\hline 2020 & 2,61 & 3.059 & 79,8 & 23.754 .743 & $3.361,01$ \\
\hline 2030 & 2,61 & 3.837 & 100,2 & 20.772 .452 & $4.821,31$ \\
\hline 2040 & 2,61 & 4.505 & 117,6 & 17.582 .673 & $6.687,29$ \\
\hline 2050 & 2,61 & 5.002 & 130,6 & 16.120 .983 & $8.098,28$ \\
\hline
\end{tabular}

Fonte: UNESCO (2010); Brasil (2009a) e cálculos deste estudo. 


\section{REFERÊNCIAS}

Amaral, N. C. A hora da verdade para o financiamento da educação brasileira: a visão dos 10\% do PIB. 2011. Brasília, DF. Disponível em: <http://www2.camara.gov.br/ atividade-legislativa/comissoes-temporarias/especiais/54a-legislatura/pl-8035-10plano-nacional-de-educacao >. Acesso em: 18 jun. 2011.

.; Pinto,J.M. R. O financiamento das IES brasileiras em 2005: recursos públicos, privados e custo dos alunos. Série-Estudos: Periódico do Mestrado em Educação da UCDB, Campo Grande: UCDB, n. 30, p. 51-70, jul./dez. 2010. [Dossiê: Política de Educação Superior no Brasil Pós-LDB/1996].

BArros, C. M. Ensino superior e sociedade brasileira: análise histórica e sociológica dos determinantes da expansão do ensino superior no Brasil (décadas de 1960/70). 2007. Dissertação (Mestrado) - Universidade Metodista de São Paulo, São Bernardo do Campo, 2007.

Brasil. Século XX: dados populacionais. Rio de Janeiro: s.d. Disponível em: <http:// seculoxx.ibge.gov.br/populacionais-sociais-politicas-e-culturais/busca-por-palavrachave/populacao>. Acesso em: 8 jul. 2013.

.Instituto Nacional de Estudos e Pesquisas Educacionais “Anísio Teixeira”. Censo da Educação Superior 2005. Brasília, DF: INEP, 2005. Disponível em: <http://www.inep. gov.br>. Acesso em: 15 maio 2012.

. Instituto Brasileiro de Geografia e Estatística. Projeção da População do Brasil por sexo e idade: 1980-2050 - Revisão 2008. Rio de Janeiro: 2008. Disponível em: <http:// www.ibge.gov.br/home/estatistica/populacao/projecao_da_populacao/2008/>. Acesso em: 9 jan. 2010.

- Ministério da Fazenda. Relatório Resumido da Execução Orçamentária do Governo Federal - dezembro de 2009. Brasília, DF: 2009a. Disponível em: <https:// www.tesouro.fazenda.gov.br/downloads/lei_responsabilidade/RRdez09.pdf >. Acesso em: 10 jan. 2010.

.Instituto Nacional de Estudos e Pesquisas Educacionais "Anísio Teixeira”. Censo da Educação Superior 2009. Brasília, DF: INEP, 2009b. Disponível em: <http://www. inep.gov.br>. Acesso em: 15 maio 2012.

. Projeto de lei n. 8.035/2010, de 20 de dezembro de 2010. Aprova o Plano Nacional de Educação para o decênio 2011-2020 e dá outras providências. Brasília, DF: 2010a. Disponível em: <http://www.camara.gov.br/internet/sileg/Prop_detalhe.asp?id=490116>. Acesso em: 2 fev. 2011.

. Instituto Brasileiro de Geografia e Estatística. Censo Demográfico de 2010. Rio de Janeiro: 2010b. Disponível em: < http://www.ibge.gov.br/home/estatistica/populacao/ censo2010/default.shtm>. Acesso em: 9 jan. 2010.

.Instituto Nacional de Estudos e Pesquisas Educacionais "Anísio Teixeira”. Censo da Educação Superior 2011. Brasília, DF: 2011a. Disponível em: <www.inep.gov.br>. Acesso em: 15 maio 2012.

.Instituto de Pesquisa Econômica Aplicada. Comunicado do IPEA n. 124. Brasília, DF: 2011b. Disponível em: <http://www.ipea.gov.br/portal/index.php?option=com_co ntente\&view=article\&id=12630 > . Acesso em: 10 jan. 2012. 
Ministério da Educação. Notas técnicas. Brasília, DF: 2011c. Disponível em: $\langle$ http://fne.mec.gov.br/imagens/pdf/notas_tecnicas_pne.pdf $\rangle$.Acesso em: 20 out. 2011. EUA - Estados Unidos da América. Agência Central de Inteligência. The World Factbook 2010. Langley, VA: Central Intelligence Agency, 2010. Disponível em: <https:// www.cia.gov/library/publications/the-world-factbook/region/region_soa.html>.Acesso em: 14 fev. 2010.

Fávero, M. L. A. Universidade do Brasil: das origens à construção. Rio de Janeiro: Editora da UFRJ, 2000.

Gomes, A. M.; Moraes, K. N. Educação superior no Brasil contemporâneo: transição para um sistema de massa. Educação E̋ Sociedade, Campinas: CEDES, v. 33 n. 118, p. 171-190, jan./mar. 2012.

Harvey, D. Condição pós-moderna. São Paulo: Edições Loyola, 2000.

OCDE - Organização para a Cooperação e Desenvolvimento Econômico. Education at a glance - 2011. OCDE Publishing: 2011. Disponível em: <http://www. oecd.org/document>. Acesso em: 20 dez. 2011.

Pinto, J. M. R. Quanto custa financiar um PNE “pra valer”? Brasília, DF: 2011. Disponível em: <http://www2.camara.gov.br/atividade-legislativa/comissoestemporarias/especiais/54a-legislatura/pl-8035-10-plano-nacional-de-educacao >. Acesso em: 20 jun. 2011.

Unesco - Organização das Nações Unidas para a Educação, a Ciência e a Cultura. Banco de Dados do Institute for Statistics - Data Centre. Paris: 2010. Disponível em: <http://stats.uis.unesco.org/unesco/TableViewer/document.aspx?>. Acesso em: 14 fev. 2010.

\section{SOBRE O AUTOR}

Nelson Cardoso Amaral é doutor em educação pela Universidade Metodista de Piracicaba (UNIMEP). Professor da Universidade Federal de Goiás (UFG).

E-mail: nelsoncardosoamaral@gmail.com

Recebido em julho de 2014

Aprovado em março de 2015 